\title{
STUDY ON ALIGNMENT TEST BASED ON ASTM E1012 AND CHINESE GUIDELINE
}

\author{
Xiaobing Zhao ${ }^{1}$, Wansheng Li $^{2}$, Minghui Fei ${ }^{3}$, Xiaolan Zheng ${ }^{4}$, William Huang ${ }^{5}$ \\ ${ }^{1}$ Wuxi Institute of Metrology and Testing, Wuxi, China, zxb@wxmtc.com \\ ${ }^{2}$ Shandong Institute of Metrology, Jinan, China, liwansheng@sdim.cn \\ ${ }^{3}$ Wuxi Institute of Metrology and Testing, Wuxi, China, fmh@wxmtc.com \\ ${ }^{4}$ Yunnan Institute of Measuring and Testing Technology, Kunming, China, zhengxlan06@163.com \\ ${ }^{5}$ GTM China Office, Shanghai, China, william.huang@gtmchina.cn
}

\begin{abstract}
This paper describes the study about alignment test on testing machine. It is based on the standards of ASTM E1012-14 (Standard Practice for Verification of Testing Frame and Specimen Alignment Under Tensile and Compressive Axial Force Application) and Chinese calibration guideline. The strain-gauge specimens of ASTM and reference extensometer of Chinese guideline were both tested on one testing machine. The test results were analyzed and compared. The traceability about both methods were also discussed. Meanwhile the amplifier was calibrated before test. It is the first time in China to performance this comparison test.
\end{abstract}

Keywords: alignment test, ASTM E1012, Chinese alignment guideline

\section{INTRODUCTION}

The alignment on testing machine is very important to obtain the right test results of material. The standard of ASTM E1012-14 [1] and Chinese guideline [2] [3] both descript how to test the alignment. But the methods are different, and the philosophy of traceability are also not same. To prove both methods reliable on testing the alignment at one testing machine, it is necessary to do a comparison test to see if there will be big tolerance by these two standards. Therefore, two laboratories in China, both own both equipment of ASTM E1012 and Chinese alignment guideline, decide to do the comparison test in 2019.

ISO 23788:2012 (Metallic materials - Verification of the alignment of fatigue testing machines) [4] also describes about alignment test, but it is very similar as ASTM E1012. The most difference between ISO 23788 and ASTM E1012 is: there are total 12 pieces of strain-gauges on three levers at the transducer according to ASTM, but there are only 8 strain-gauges on two levers according to ISO.

The details and difference between ASTM E1012 and Chinese guideline are: the specimen, the procedure, the calculation, the classification (deviation) and the traceability. They are described in section 2 to section 5 .

\section{THE EQUIPMENTS}

According to ASTM E1012, there are four strain-gauges at same lever but different position on alignment specimen (so-call alignment transducer). Total 12 or 8 pieces of strain-gauges on 3 or 2 levers at the transducer. As Figure 1:

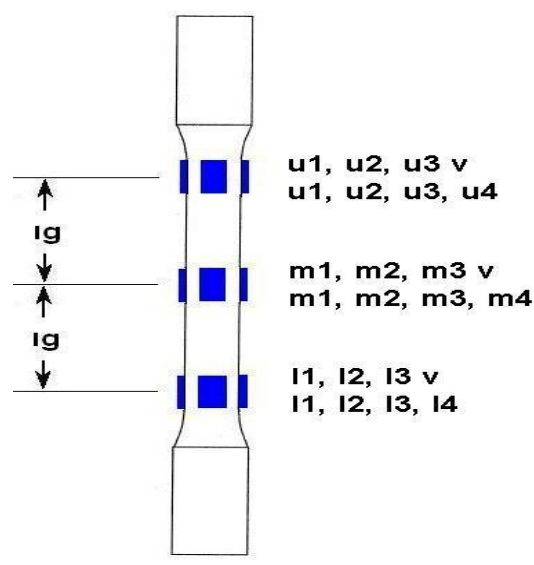

Figure 1: Strain-gauge transducer

The equipment to be performance alignment test consist: an alignment specimen with 12 pieces of strain-gauges, amplifier of 12 channels, the software. They are called alignment tool kit by the product from ZwickRoell, a Germany testing machine manufacturer. As Figure 2.

The alignment specimen details (sharp, dimension) as Figure 3. 


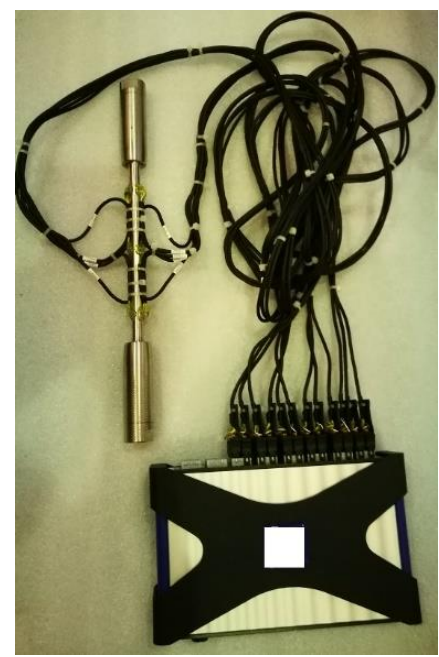

Figure 2: Alignment tool kit from ZwickRoell

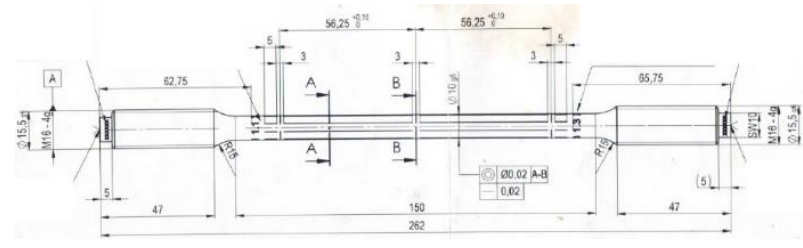

Figure 3: Alignment specimen

The amplifier is type quantumX MX1615B. Excitation voltage is $10 \mathrm{~V}$ and full-bright are set in the software. 12 channels of this amplifier are used to be connected to the alignment specimen.

According to Chinese guideline JJG 475-2008: verification of electric testing machine, and JJG 556-2011: verifications of uniaxial fatigue testing machine [2] [3], the alignment kit is twins' extensometers and specimens, as Figure 4.

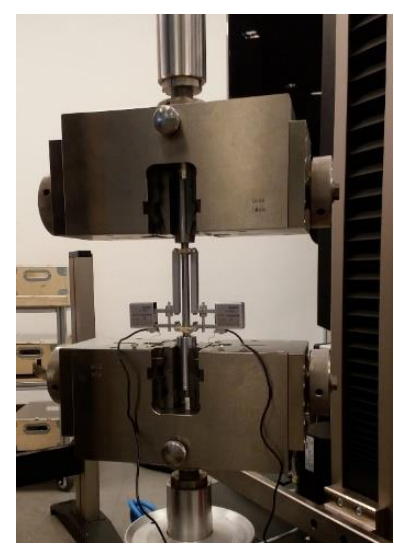

Figure 4: twins' extensometers on specimen

The twins' extensometers mean there are two extensometers: one is attached on the left side of specimen and another is on the right side. The extensometer is used for measuring the elongation of the specimen during tensile test. Theoretically the elongation of both sides of specimen should be same if the alignment of the testing machine is perfect.

The specimen's specification is descripted as in Table 1 and Figure 5.

\begin{tabular}{|c|c|c|c|c|}
\hline $\begin{array}{c}\text { Fmax of testing } \\
\text { machine in } \mathrm{kN}\end{array}$ & $\begin{array}{c}\text { diam.d } \\
\text { in } \mathrm{mm}\end{array}$ & $\begin{array}{c}\text { gauge } \\
\text { length Lo } \\
\text { in mm }\end{array}$ & $\begin{array}{c}\mathrm{L} \text { in } \\
\mathrm{mm}\end{array}$ & material \\
\hline$[100---600)$ & 10 & 100 & 130 & $\begin{array}{c}\text { steel } \\
\text { No.45 }\end{array}$ \\
\hline$(30---100)$ & 10 & 100 & 130 & $\begin{array}{c}\text { alloy } \\
\text { steel }\end{array}$ \\
\hline
\end{tabular}

Table 1: the dimension of the specimen

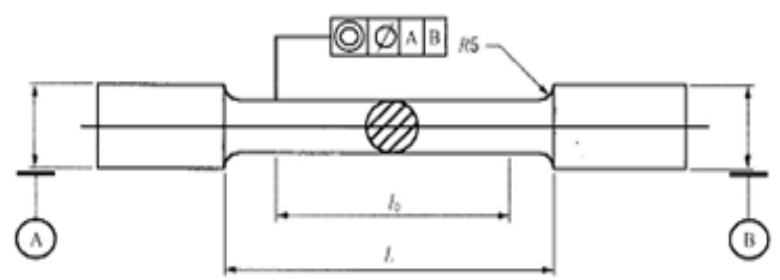

Figure 5: the drawing of the specimen

\section{PROCEDURE}

We use a ZwickRoell testing machine Z050 to do test. The capacity of the machine force is $50 \mathrm{KN}$. The classification of this testing machine is class 0.5 .

\subsection{According to ASTM E1012-14:}

1. clamp the alignment transducer at the top grip, zero the signal, clamp the lower grip.

Apply a small force to see all signal ok and then remove the force.

2. increase the force and apply it to $4 \%, 6 \%$ and $8 \%$ of the capacity of the testing machine, that means $2 \mathrm{kN}, 3 \mathrm{kN}$, and $4 \mathrm{kN}$. Record the measurement value. And calculate all the data automatic by software.

(The original is to apply the force to 10\%, 20\% and $40 \%$ of the machine capacity, here we apply $4 \%$, $6 \%$ and $8 \%$ of the machine capacity)

3 . remove the force to zero. Change the position of the alignment transducer from position $0^{\circ}$ to $180^{\circ}$ and repeat the step 2.

4. remove the force to zero. Change the position from $180^{\circ}$ back to $0^{\circ}$, and repeat step 2 .

\subsection{According to Chinese guideline:}

1. clamp the specimen on both grips of testing machine

2. apply the force of $0.5 \%$ of the machine and attach the twin's extensometers at the position of 1 and 3 on the specimen as Figure 6.

Apply the force to $1 \%$ of the machine and zero the signal of both extensometers. Apply to the force to $10 \%$ of the machine. That means the pre-apply. Do it three times.

3. remove the force to zero. Apply the force to $1 \%$ of the machine and zero the signal of both extensometers. Increase the force to $4 \%, 6 \%$ and $8 \%$ of the machine. Record all the data.

(The original is to increase the force to $4 \%, 6 \%$, $8 \%$ and $10 \%$ of the machine capacity, here we apply $4 \%, 6 \%$ and $8 \%$ of the machine capacity) 
4. change the extensometers to positions 2 and position 4. Same procedure as step 2 and 3 .
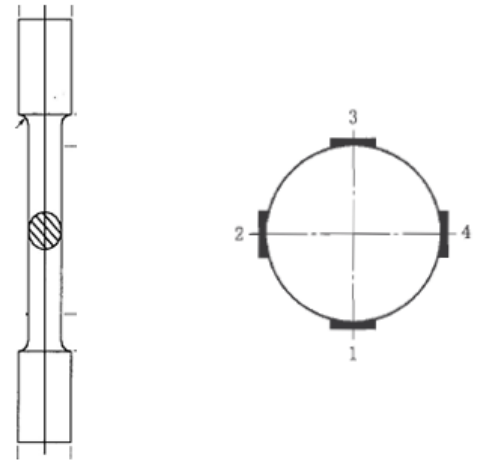

Figure 6: the positions for twins' extensometers attached

\section{DATA ANALYSISI}

According to ASTM E1012, the Cylindrical strain-gauged alignment specimen use following equations:(As Figure 7)

axial strain,

$$
a=\left(\frac{e_{1}+e_{2}+e_{3}+e_{4}}{4}\right)
$$

where:

$e_{1}, e_{2}, e_{3}$, and $e_{4}=$ the measured strains at the four locations and the subscript indicates the order around the strain-gaged alignment transducer.

local bending strain,

$$
\begin{aligned}
& b_{1}=e_{1}-a \\
& b_{2}=e_{2}-a \\
& b_{3}=e_{3}-a \\
& b_{4}=e_{4}-a
\end{aligned}
$$

and maximum bending strain,

$$
B=\frac{1}{2} \sqrt{\left(b_{1}-b_{3}\right)^{2}+\left(b_{2}-b_{4}\right)^{2}}
$$

and

$$
P B=\left(\frac{B}{a}\right) \times 100
$$

Figure 7: the equations of $P B$

$\boldsymbol{P B}$ is the percent bending, which is the value of the alignment.

From the test 3.1, all data were collected. Here we show the data from the middle lever of the straingauge, as in Table 2.

In ASTM E1012, the original "record data points

\begin{tabular}{|c|c|c|c|c|}
\hline Force & \multicolumn{2}{|c|}{ Position } & $P B(\%)$ & $\begin{array}{c}P B \\
\text { (Ave) }\end{array}$ \\
\hline \multirow{3}{*}{$2 \mathrm{kN}$} & \multirow{3}{*}{ middle } & $0^{\circ}$ & 25.3 & \multirow{3}{*}{21.5} \\
\hline & & $180^{\circ}$ & 16.89 & \\
\hline & & $0^{\circ}$ & 22.3 & \\
\hline \multirow{3}{*}{$3 \mathrm{kN}$} & \multirow{3}{*}{ middle } & $0^{\circ}$ & 17.42 & \multirow{3}{*}{14.3} \\
\hline & & $180^{\circ}$ & 11.62 & \\
\hline & & $0^{\circ}$ & 13.94 & \\
\hline \multirow{3}{*}{$4 \mathrm{kN}$} & \multirow{3}{*}{ middle } & $0^{\circ}$ & 14.08 & \multirow{3}{*}{10.7} \\
\hline & & $180^{\circ}$ & 8.98 & \\
\hline & & $0^{\circ}$ & 9.12 & \\
\hline
\end{tabular}
at $10 \%, 20 \%$ and $40 \%$ of the force transducer range or testing machine capacity", but here we only apply the force to $4 \%, 6 \%$ and $8 \%$, and the best value of $P B$ is 10.7 at $4 \mathrm{kN}$ ( $8 \%$ of the machine capacity of $50 \mathrm{~K})$, because we try to make the same force apply as Chinese calibration guideline.
Table 2: the data of the middle lever of the straingauge

According to the Chinese guideline, the value of $\boldsymbol{e}$ is the alignment specification of the testing machine. It uses following equations: (As Figure 8)

$$
\overline{\Delta L}=\left(\Delta L_{1}+\Delta L_{2}+\Delta L_{3}+\Delta L_{4}\right) / 4
$$

$$
\Delta L_{b i}=\Delta L_{i}-\overline{\Delta L}
$$

$$
\begin{gathered}
\Delta L_{b \max }=\frac{1}{2} \sqrt{\left(\Delta L_{b 1}-\Delta L_{b 3}\right)^{2}+\left(\Delta L_{b 2}-\Delta L_{b 4}\right)^{2}} \\
\Delta L_{b \max }=\frac{1}{2} \sqrt{\left(\Delta L_{1}-\Delta L_{3}\right)^{2}+\left(\Delta L_{2}-\Delta L_{4}\right)^{2}} \\
e=\Delta L_{B \max } / \overline{\Delta L} \times 100 \%
\end{gathered}
$$

Figure 8: the equations of $e$

From the test 3.2, we collect the data of $\boldsymbol{e}$ as in Table 3.

\begin{tabular}{|c|c|}
\hline Force & $\boldsymbol{e}(\boldsymbol{\%})$ \\
\hline $2 \mathrm{kN}$ & 10.3 \\
\hline $3 \mathrm{kN}$ & 7.3 \\
\hline $4 \mathrm{kN}$ & 5.4 \\
\hline
\end{tabular}

Table 3: the data by test 3.2

Test results of test 3.1 and test 3.2 are compared as in Table 4.

\begin{tabular}{|c|c|c|c|}
\hline \multicolumn{2}{|c|}{ Force } & $\boldsymbol{P B}(\boldsymbol{\%})$ & $\boldsymbol{e}(\boldsymbol{\%})$ \\
\hline $\begin{array}{c}4 \% \text { of } \\
\text { machine }\end{array}$ & $2 \mathrm{kN}$ & 21.5 & 10.3 \\
\hline $\begin{array}{c}6 \% \text { of } \\
\text { machine }\end{array}$ & $3 \mathrm{kN}$ & 14.3 & 7.3 \\
\hline $\begin{array}{c}8 \% \text { of } \\
\text { machine }\end{array}$ & $4 \mathrm{kN}$ & 10.7 & 5.4 \\
\hline
\end{tabular}

Table 4: the results compared 
The $P B$ results are almost exactly double the $e$ results. But it should be no coincidence because the classification is different as discussion later.

\section{DISCUSSION}

The classification of alignment by ASTM E1012: and Chinese calibration guideline is different, as in Table 5.

\begin{tabular}{|c|c|}
\hline $\begin{array}{c}\text { ASTM E1012 } \\
\text { Classification }\end{array}$ & $\begin{array}{c}\boldsymbol{P B} \\
(\boldsymbol{\%})\end{array}$ \\
\hline 5 & 5 \\
\hline 8 & 8 \\
\hline 10 & 10 \\
\hline
\end{tabular}

\begin{tabular}{|c|c|}
\hline $\begin{array}{c}\text { Classification } \\
\text { of testing } \\
\text { machine }\end{array}$ & $\begin{array}{c}\boldsymbol{e} \\
(\boldsymbol{\%})\end{array}$ \\
\hline 0.5 & 12 \\
\hline 1 & 15 \\
\hline 2 & 20 \\
\hline
\end{tabular}

Table 5: the different classification.

The standard of ASTM only talks about the alignment classification, instead of the machine. The Chinese guideline takes care the machine must fulfil the requirement of the alignment.

The data from test 3.1 does not apply enough force on the strain-gauge specimen according to ASTM E1012. Therefore, it cannot give decision that $P B$ of 10.7 does not fulfil class 10 .

The data from 3.2 test shows that the machine full fill class 0.5 , because the alignment of $e$ is $10.3 \%$, which is within the tolerance of $12 \%$.

Additional topic need taken care is the traceability. In ASTM E1012, there mentioned: "8.1.1 Calibration of strain-gaged alignment transducers is not required by this standard. Traceable national standards do not generally exist for such calibrations. However, great care should be taken in the manufacture of strain-gage alignment transducers used for the determination of alignment" That means only the amplifier can be calibrated.

We did calibration as in Figure 9 for this. The standard signal is created by a device.

The deviation between standard signal and amplifier $(\mathrm{mV} / \mathrm{V})$ is less than $-0.3 \%$. Its fine. The details data as shown in Table 6.

\begin{tabular}{|c|c|c|c|}
\hline standard & $\begin{array}{c}\text { amplifier } \\
\mathrm{mV} / \mathrm{V}\end{array}$ & $\begin{array}{c}\text { amplifier } \\
\mu \mathrm{m} / \mathrm{m}\end{array}$ & deviation \% \\
\hline 0 & 0.0003 & 0.4 & - \\
\hline 0.25 & 0.2499 & 254.6 & -0.04 \\
\hline 0.5 & 0.4997 & 509 & -0.06 \\
\hline 0.75 & 0.7485 & 763 & -0.20 \\
\hline 1 & 0.9977 & 1017 & -0.23 \\
\hline
\end{tabular}

Table 6: calibration data of amplifier.
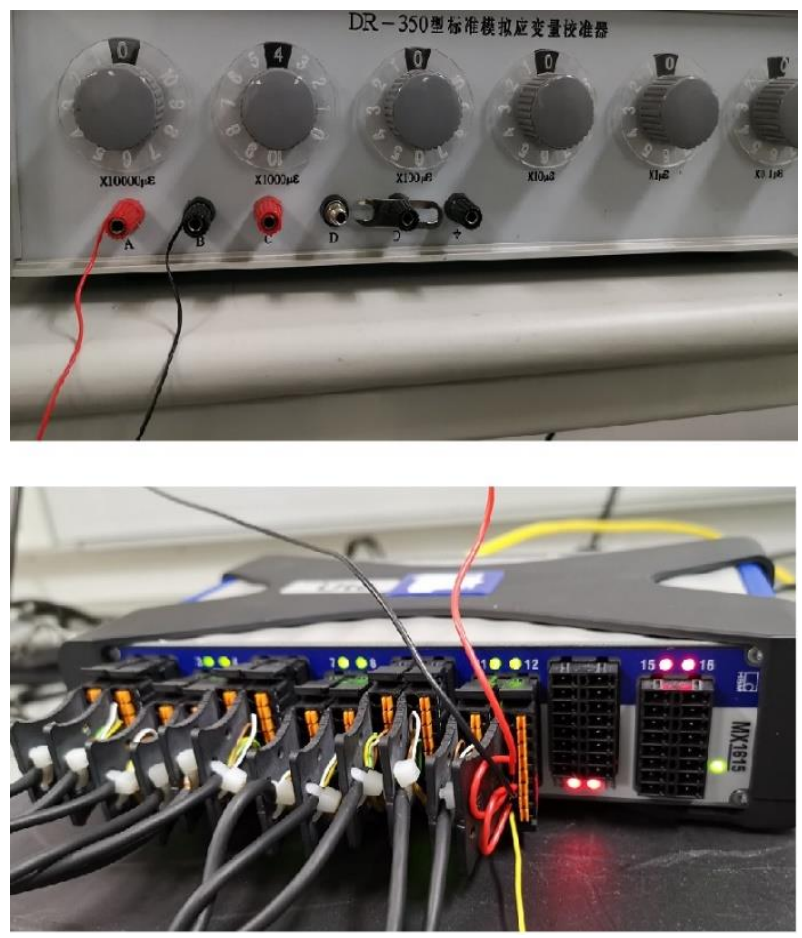

Figure 9: The standard signal (above), and the amplifier to be calibrated (below)

Concerning the calibration on twins' extensometers of Chinese, its easy: calibrate the two extensometers one by one. Each is done by a master extensometer. They can be traceability to the primary standard of length. That mean all the Chinese alignment kit can be calibrated.

\section{SUMMARY}

The main difference between the standard of ASTM E1012-14 and Chinese calibration guideline about alignment are classification, tool kit hardware, and the force apply.

ASTM is more accuracy on alignment specificity of testing machine. But there is no solution for the whole traceability.

The method of Chinese guideline is easier to handle and can be traceability.

Both methods are reliable to determine the alignment of the material testing machine.

\section{REFERENCES}

[1] ASTM E1012-14. Standard Practice for Verification of Testing Frame and Specimen Alignment Under Tensile and Compressive Axial Force Application.

[2] JJG 475-2008: verification of electric testing machine

[3] JJG 556-2011. verifications of uniaxial fatigue testing machine.

[4] ISO 23788:2012 (Metallic materials - Verification of the alignment of fatigue testing machines) 